\title{
Locally Adapted Mimulus Ecotypes Differentially Impact Rhizosphere Bacterial and Archaeal Communities in an Environment-Dependent Manner
}

\author{
Alan W. Bowsher, ${ }^{1,2}$ Patrick J. Kearns, ${ }^{1,2}$ Damian Popovic, ${ }^{3,4}$ David B. Lowry, ${ }^{2,3,4,5}$ and Ashley Shade ${ }^{1,2,4,5, \dagger}$ \\ ${ }^{1}$ Department of Microbiology and Molecular Genetics, Michigan State University, East Lansing, MI \\ ${ }^{2}$ Plant Resilience Institute, Michigan State University, East Lansing, MI \\ ${ }^{3}$ Department of Plant Biology, Michigan State University, East Lansing, MI \\ ${ }^{4}$ Program in Ecology, Evolutionary Biology and Behavior, Michigan State University, East Lansing, MI \\ ${ }^{5}$ DOE Great Lakes Bioenergy Research Center, Michigan State University, East Lansing, MI
}

Accepted for publication 28 October 2019.

\section{ABSTRACT}

Plant root-microbe interactions influence plant productivity, health, and resistance to stress. Although there is evidence that plant species and even genotypes can alter soil microbial community structure, environmental conditions can potentially outweigh plant genetic effects. Here, we used a reciprocal transplant experiment to understand the contributions of the environment and the host plant to rhizosphere microbiome composition in locally adapted ecotypes of Mimulus guttatus (syn. Erythranthe guttata). Two genotypes of a coastal ecotype and two genotypes of an inland ecotype were planted at coastal and inland sites. After 3 months, we collected rhizosphere and bulk soil and assessed microbial communities by $16 \mathrm{~S}$ rRNA gene sequencing. We found that local environment (coastal versus inland site) strongly influenced rhizosphere communities, at least in part due to distinct local microbial species pools. Host identity played a smaller role: at each site, the ecotypes exhibited remarkably similar composition of microbial communities at the class level, indicating that divergent $M$. guttatus ecotypes recruit phylogenetically similar rhizosphere communities, even in environments to which they are maladapted. Nevertheless, the two ecotypes significantly differed in community composition at both sites due, in part, to an exclusive set of taxa associated with each ecotype. They also differed in alpha diversity at the inland site. Although this indicates that locally adapted $M$. guttatus ecotypes are genetically diverged in factors shaping rhizosphere communities, our findings highlight the context-specific interactions between host identity and local environment that shape those communities.

Keywords: 16S rRNA gene, metagenomics, microbiome, Mimulus guttatus, natural habitats, plant-microbe interactions, rhizosphere and phyllosphere, root microbiome, soil ecology
The rhizosphere (the narrow zone of soil surrounding plant roots) is a highly diverse and active microenvironment. In addition to

${ }^{\dagger}$ Corresponding author: A. Shade; shadeash@msu.edu

Funding: This work was supported in part by funding from the Michigan State University Plant Resilience Institute to A. Shade and D. B. Lowry, a National Science Foundation Division of Integrative Organismal Systems grant (IOS-1855927) to D. B. Lowry, and National Science Foundation Division of Environmental Biology grant (DEB-1655425) and Division of Molecular and Cellular Biosciences grant (MCB1817377) to A. Shade. Computational resources were provided by the Michigan State University Institute for Cyber-Enabled Research.

*The $e$-Xtra logo stands for "electronic extra" and indicates that three supplementary figures and three supplementary tables are published online.

The author(s) declare no conflict of interest. distributed under the CC BY-NC-ND 4.0 International license. influencing soil structure, moisture, and nutrient availability (Angers and Caron 1998; Marschner et al. 1987; McKinney and Cleland 2014), plant roots continuously supply labile carbon to the soil through root exudation. These continual carbon inputs recruit a host of soil microbes to the rhizosphere (Bressan et al. 2009; Bulgarelli et al. 2012; Chaparro et al. 2014; Zhalnina et al. 2018), often resulting in distinct microbial communities compared with the surrounding bulk soil (Berendsen et al. 2012; Bever et al. 2012; Philippot et al. 2013). Rhizosphere microbial communities can strongly impact plant health and productivity, altering plant morphology (Friesen et al. 2011), phenology (Wagner et al. 2014), and plant resistance to both biotic (Busby et al. 2016; Ritpitakphong et al. 2016; Santhanam et al. 2015;) and abiotic stresses (Lau and Lennon 2011, 2012). Nevertheless, despite the critical importance of rhizosphere communities for plant productivity, the factors shaping the rhizosphere microbiome are complex and not fully understood (Berg and Smalla 2009; Lareen et al. 2016; Sasse et al. 2018). 
One factor that can strongly influence rhizosphere community composition is plant host identity. Plant species and even genotypes within species can differ in rhizosphere community structure when planted in a common environment (Aira et al. 2010; Berg et al. 2002; Bouffaud et al. 2012; Bowen et al. 2017; Edwards et al. 2015; Fitzpatrick et al. 2018; Mahoney et al. 2017). This finding is often suggested to result, at least in part, from species-specific root exudation patterns recruiting different community members (Marschner et al. 2001). Indeed, numerous studies suggest root exudation is the primary mechanism by which plants mediate rhizosphere community assembly and function (Broeckling et al. 2008; Carvalhais et al. 2015; Haichar et al. 2008; Hu et al. 2018). Other species- or genotypespecific factors could also contribute, such as differences in rooting depth (Aleklett et al. 2015) and root architecture (Pérez-Jaramillo et al. 2017), given that microbial community composition can shift with soil depth (Fierer et al. 2003; Ko et al. 2017).

In addition to the influence of plant host identity, environmental factors can also shape the rhizosphere microbiome. For example, the local environment directly affects rhizosphere communities by determining the available source pool of microorganisms, since soil microbial communities are structured by both spatial and environmental gradients (Fierer and Jackson 2006; Rath et al. 2019; Xue et al. 2018). Local environmental conditions can also indirectly influence rhizosphere community composition by affecting plant or microbial physiology (Aira et al. 2010). For example, many environmental factors can influence rooting architecture (LopezBucio et al. 2003; Niu et al. 2013; Kiba and Krapp 2016) and root exudation (Carvalhais et al. 2011; Gargallo-Garriga et al. 2018; Gu et al. 2016; Henry et al. 2007; Zhang et al. 1991), thereby influencing rhizosphere composition. As a result, environmental conditions can outweigh the effects of plant host identity (i.e., differences among plant species or genotypes) in structuring rhizosphere communities (Marschner et al. 2004; Peiffer et al. 2013). While considerable recent microbiome research has been focused on economically important crops, less is known about the interplay between plant host and the local environment for wild plants, which experience relatively higher variability in their local environments than plants grown in managed systems.

In this study, we used a field reciprocal transplant experiment to better understand the contributions of both the environment and host plant identity to rhizosphere microbiome composition. We used two locally adapted ecotypes (coastal versus inland) of yellow monkeyflower, Mimulus guttatus (syn. Erythranthe guttata (Fisch. ex DC.) G.L. Nesom), a model species for ecological and evolutionary genomics (Twyford et al. 2015; Wu et al. 2008). Coastal and inland ecotypes are highly locally adapted to their respective habitats (Hall and Willis 2006; Hall et al. 2010; Lowry and Willis 2010; Lowry et al. 2008). Inland habitats of M. guttatus experience a hot summer drought, for which these populations have evolved an early flowering, annual life-history strategy to escape from the long period of low soil water availability (Hall and Willis 2006; Lowry et al. 2008). In contrast, coastal habitats typically are much cooler as a result of proximity to the Pacific Ocean, which drives the production of summer sea fog. However, coastal populations of M. guttatus contend with pervasive oceanic salt spray, for which they are locally adapted (Lowry et al. 2008, 2009). Here, we planted coastal and inland ecotypes of $M$. guttatus in both coastal and inland sites and investigated rhizosphere and bulk soil microbial community composition after 3 months of growth.

\section{MATERIALS AND METHODS}

Experimental design. To establish the relative role of environment (coastal versus inland site) and ecotype (coastal perennial versus inland annual) on the $M$. guttatus microbial rhizosphere community, we leveraged a reciprocal transplant experiment conducted in Sonoma County, CA, U.S.A. in the spring of 2017 (Popovic and Lowry, in press). Briefly, accessions from two coastal perennial populations (SWB-11, 39.0359 N, -123.6905 W; MRR$13,38.4564 \mathrm{~N},-123.1409 \mathrm{~W})$ and two inland annual populations $(\mathrm{LMC}-24,38.8640 \mathrm{~N},-123.0840 \mathrm{~W} ;$ OCC-31, 38.4095 $\mathrm{N},-122.9355 \mathrm{~W})$ native in the same region of Northern California were used for the experiment. Source populations for the SWB and LMC seeds are in Mendocino County, CA, and have been used in many recent studies of genetics and local adaptation in this system (Lowry et al. 2008, 2009). The MRR and OCC source populations are located in Sonoma County, CA (Popovic and Lowry, in press). All accessions were grown for at least one generation in the Michigan State University greenhouses to control for maternal effects.

On 1 February 2017, seeds were planted on wet Sunshine Soil Mix \#1 (SunGro Horticulture, Agawam, MA), which is a mix of sphagnum peat moss, perlite, and dolomitic lime, as well as macroand micronutrients. Seeds were planted in two $54.28 \times 27.94 \mathrm{~cm}$ potting trays per genotype. Seeds were then stratified at $4^{\circ} \mathrm{C}$ for 10 to 17 days (10 days for coastal accessions, 17 days for inland accessions) and subsequently germinated at the University of California, Berkeley's Oxford Track greenhouse facilities under 16-h days, supplied by supplemental lighting. Different lengths of stratification were used for the two ecotypes because the inland ecotype germinates earlier and grows faster than the coastal genotype early in development. This allowed seedlings to be transplanted to the field later at the same developmental stage. On 28 February, all seedlings were moved to the greenhouse at the Bodega Marine Reserve (https://bml.ucdavis.edu/bmr/) in Bodega Bay, CA. The Bodega greenhouse has no supplemental lights and minimal temperature controls.

We transplanted seedlings at the four-leaf stage into the coastal site on 8 March 2017 and into the inland site on 9 March 2017. The coastal site was located at the Bodega Marine Reserve, Bodega Bay, $\mathrm{CA}$, in a perennial seep at the south end of Horseshoe Cove $(38.315716 \mathrm{~N},-123.068625 \mathrm{~W} ; \sim 60 \mathrm{~m}$ from the ocean). The inland site was planted in a seasonal grassland seep at the Pepperwood Preserve in Santa Rosa, CA (38.575545 N, -122.700851 W; $39.84 \mathrm{~km}$ from the ocean). Native populations of M. guttatus are located in both seeps. Prior to planting, three plots $(1 \times 1 \mathrm{~m})$ were cleared of native vegetation at each site using a hand-held hoe, such that both the aboveground and much of the belowground portion of native plants was removed. The experimental design was a complete randomized block design: each plot included a total of 100 plants ( $N=25$ of each genotype), which were all equally spaced from one another and were haphazardly randomized throughout each plot $(N=100$ per plot, 300 per site, 600 total). Although most of the potting soil naturally fell free from the root system during transplant, a small amount of potting soil was unavoidably transplanted along with the roots. Plants were then grown for 3 months until being harvested for rhizosphere community analyses.

Sample collection and processing. On 13 to 15 June, five replicate $M$. guttatus rhizosphere soils were collected from each genotype at each field environment from plants that were spatially distributed across all three plots. Rhizosphere soil was isolated by uprooting the plant with a trowel, discarding excess soils from around the roots, and shaking what soil remained attached to the root into a sterile Whirl-Pak bag. It was impossible to avoid the original potting soil when collecting rhizosphere samples: we expect that the small amount of potting soil transplanted with the initial transplants blended quickly with the surrounding soil, as the plants were grown in very wet seeps with a constant low-level flow 
of water. Rhizosphere soils were homogenized with an ethanolsterilized metal spatula, aliquoted into cryovials, flash frozen in liquid nitrogen, and stored on ice before being transferred to dry ice for transport to Michigan State University. Above- and belowground tissue for each plant was stored in a paper bag and transported at ambient temperature to the lab at Michigan State University, washed with distilled water, and dried for 1 week at $60^{\circ} \mathrm{C}$ before measuring dry biomass. In addition, bulk soil cores $(10 \mathrm{~cm} \times 2 \mathrm{~cm})$ were collected at each site. Five replicate soil samples (each comprised of three homogenized soil cores from a given plot) collected randomly from each site were collected, sieved, and stored in a sterile Whirl-Pak bag on ice, and then transferred to dry ice for transport to Michigan State University. Bulk and rhizosphere soil samples were subsequently analyzed at the Michigan State University Soil and Plant Nutrient Laboratory for phosphorus, potassium, calcium, magnesium, copper, nitrate, percent organic matter, sodium, ammonium, $\mathrm{pH}$, and sulfur (see 'Links' tab at the following web address for soil testing methods: http://www.spnl.msu.edu/). Percent nitrogen was assessed using the Kjeldahl method (Kjeldahl 1883), while percent moisture was determined from the loss of mass in dried soils.

DNA extraction and sequencing. DNA was extracted from the five replicate rhizosphere soil samples of each $M$. guttatus genotype from each environment ( $n=40$ samples; five replicates of each of four genotypes at each of two sites), as well as from 10 bulk soil samples (five replicates from each of two sites). We used the MoBio PowerSoil Total DNA Isolation Kit (Carlsbad, CA) following the manufacturer's instructions, using $0.40 \mathrm{~g}$ of soil per rhizosphere sample and $0.23 \mathrm{~g}$ per bulk soil sample. Extracted DNA was quantified fluorometrically with the Qubit (ThermoFisher, Waltham, MA). DNA from each sample was diluted to $<10 \mathrm{ng}^{\mu \mathrm{l}^{-1} \text { for }}$ paired-end amplicon sequencing using the dual-indexed primer pair 515F/806R (Kozich et al. 2013). Samples were prepared for sequencing by the Michigan State University Genomics Core (East Lansing, MI) including PCR amplification and library preparation using the Illumina TruSeq Nano DNA Library Preparation Kit. Paired-end, 250 bp reads were generated on an Illumina MiSeq at the Michigan State University Genomics Core, which also provided standard Illumina quality control and sample demultiplexing.

Sequence processing. The rhizosphere and bulk soil sequencing datasets were analyzed together. Paired-end reads were merged using USEARCH v10.0.240 (Edgar 2010) with -fastq_maxdiffs set to 10 , -fastq_minmergelen set to 250, and -fastq_maxmergelen set to 300 . Primer-binding regions were removed using cutadapt v1.18 (Martin 2011), then reads were quality-filtered (with -fastq_maxee set to 1), dereplicated, filtered of singletons, and clustered into zeroradius operational taxonomic units (OTUs) using the USEARCH v9.2.64/v10.0.240 and UNOISE pipeline (Edgar 2016). Taxonomy annotations were assigned in QIIME v1.9.0 (Caporaso et al. 2010) using UCLUST (Edgar 2010) against the SILVA rRNA database v123 (Quast et al. 2013) at a similarity threshold of 0.9, and were added to the .biom file using the biom-format package (McDonald et al. 2012). Sequences that were unassigned at the phylum level, along with those matching chloroplasts or mitochondria, were excluded from analyses. Representative sequences were aligned using MUSCLE 3.8.1 (Edgar 2004), and FastTree v2.1.10 (Price et al. 2009, 2010) was used to build a phylogenetic tree. Samples were rarefied to the minimum number of sequences observed per sample $(22,354)$ for all subsequent analyses. Although randomly subsetting the data through rarefying can influence taxa abundances, the single_rarefaction.py command in QIIME was used for reproducibility of our analyses. We calculated species richness, Shannon diversity, and phylogenetic diversity in QIIME, as well as beta diversity using weighted UniFrac distance (Lozupone and
Knight 2005) for principal coordinates analysis (PCoA). Jaccard distances (Jaccard 1901) were calculated using the vegdist function of the vegan v2.5-2 package (Oksanen et al. 2018) in R 3.5.0 ( $R$ Core Team 2018).

Statistical analysis. All statistical analyses were conducted in R. We assessed differences in soil chemistry between sites using $t$ tests. The homogeneity of variance assumption was assessed using both Bartlett's and Levene's tests (Levene 1960; Snedecor and Cochran 1989) in the car package (Fox and Weisberg 2011), while normality of residuals was assessed using the Shapiro-Wilk test. The Welch's $t$ test was used when the homogeneity of variance assumption was not met, while the Wilcoxon rank sum test was used when residuals were not normally distributed. Differences in alpha diversity metrics and plant traits were assessed using two-way analysis of variance (ANOVA) (with 'ecotype' and 'site' as main factors, and their interaction) followed by a Tukey posthoc test. Shoot mass data were log-transformed in order to meet the assumptions of ANOVA. For Shannon diversity, a single outlier (greater than three standard deviations from the group mean) was removed to meet ANOVA assumptions; results are reported both including and excluding the outlier.

For the sequencing dataset, we assessed the effects of abiotic (phosphorus, potassium, calcium, magnesium, copper, percent organic matter, sodium, nitrate, ammonium, percent nitrogen, and sulfur) parameters on microbial community composition by fitting variables to the principal coordinates analysis (PCoA) scores generated from weighted UniFrac (for phylogenetic community structure) as well as Jaccard distances (for presence/absence of taxa) using the envfit function of vegan (Oksanen et al. 2018). We included parameters that had significant explanatory value $(P<0.05)$ as vectors in the ordinations. Differences in community composition across categorical groups (rhizosphere versus bulk soil, inland versus coastal sites, as well as their interaction) were calculated with permutational multivariate ANOVA (PERMANOVA) using 999 iterations (Anderson 2001). We also tested for differences in group dispersions with PERMDISP (Anderson 2006). Next, we selected the twenty most abundant taxa at the Class level and tested for differences in abundance of these taxa using $t$ tests with a false discovery rate (FDR)-adjusted $P$ value for multiple comparisons. Within each site, we compared inland versus coastal ecotypes, as well as genotypes within ecotypes.

We next explored differences between ecotypes and sites at the individual OTU level to better understand the factors distinguishing their microbial communities. We conducted an indicator species analysis, which aims to determine which taxa are characteristic of a given treatment group, taking into account the abundances of a given taxon for each treatment group (specificity), as well as the proportion of samples in each treatment group in which that taxon occurs (fidelity) (De Cáceres and Legendre 2009; De Cáceres et al. 2010). We used the multipatt function (De Cáceres et al. 2010) in the R package indicspecies (De Cáceres and Legendre 2009). Next, we tested for ecotype differences in relative abundance of individual OTUs using $t$ tests with FDR-adjusted $P$ values for multiple comparisons. Finally, we generated Venn diagrams using the $\mathrm{R}$ packages gplots (Warnes et al. 2019) and VennDiagram (Chen 2018) to assess differences in the presence/absence of individual taxa between the two ecotypes. An OTU was designated as 'present' in a given ecotype if at least one sequencing read representing that OTU was found in at least one sample of that ecotype; otherwise it was 'absent'. Data were visualized using a combination of the R packages ggplot2 v2.2.1 (Wickham 2009), reshape2 v.1.4.3 (Wickham 2007), gridExtra 2.3 (Baptiste 2017), and cowplot v0.9.2 (Wilke 2017). Package plyr v.1.8.4 (Wickham 2011) was used for data summaries. 
Data availability and computing workflows. Raw reads were submitted to the NCBI Sequence Read Archive under accession numbers PRJNA451377 (rhizosphere samples) and PRJNA526056 (bulk soil samples). All plant and environmental data, as well as computational workflows and custom scripts, are available on GitHub (https://github.com/ShadeLab/PAPER_MimulusRecipTransplant_ Phytobiomes_2020).

\section{RESULTS}

Soil characteristics and plant performance differ across sites. The coastal and inland sites had very different soil properties (Table 1). All measured abiotic parameters significantly differed between the coastal and inland sites, with the exception of $\mathrm{pH}$, ammonium, nitrate, and percent nitrogen. Plants also performed differently in the coastal and inland sites.

Plants in the coastal site were overall larger in both shoot mass $(F=13.164, P<0.001)$ and root mass $(F=23.359, P<0.001)$ than plants at the inland site (Supplementary Fig. S1). In addition, the coastal ecotype was overall significantly larger in both shoot mass $(F=8.7571, P=0.006)$ and root mass $(F=5.637, P=0.023)$ than the inland ecotype.

Sequencing summary. In total, 49 samples were sequenced, resulting in a $3,119,029$ sequencing reads (average of 63,654 reads per sample). Of those, 2,503,095 sequences remained after merging (80.3\%) and 2,433,943 of the merged sequences passed the ensuing quality filter (97.2\%). After removing singletons and determining representative sequences, a total of 2,232,822 sequences mapped to OTU definitions, and 2,130,143 of those (95.4\%) were assigned a taxonomy that was neither mitochondria nor chloroplast. Altogether, this resulted in a minimum of 22,354 reads per sample and a maximum of 94,669 reads per sample (average of 43,472 reads per sample). After rarefying (i.e., subsampling) the dataset to 22,354 reads per sample, there were an average of 3,902 OTUs per sample. Supplementary Table S1 provides sequencing statistics for each sample.

Site and ecotype influence microbial community composition. A principal coordinates analysis based on weighted UniFrac distances found that two axes captured nearly $60 \%$ of the variation in the amplicon sequencing dataset $(45.8 \%$ variation explained for

TABLE 1

Soil characteristics (mean with standard error in parentheses) for bulk soils collected from Mimulus guttatus planted in two environments

\begin{tabular}{lccr}
\hline Soil variable & Coastal site & Inland site & $P$ value \\
\hline $\mathrm{pH}$ & $6.08(0.1)$ & $6.16(0.15)$ & 0.398 \\
\hline Phosphorus $(\mathrm{ppm})$ & $17.4(2.3)$ & $3.4(0.6)$ & 0.001 \\
\hline Potassium $(\mathrm{ppm})$ & $49.2(9.3)$ & $171.4(16.4)$ & $<0.001$ \\
\hline Calcium $(\mathrm{ppm})$ & $788.2(121.7)$ & $2,518.4(91.8)$ & $<0.001$ \\
\hline Magnesium $(\mathrm{ppm})$ & $227.4(19.7)$ & $1,603.8(162.4)$ & 0.008 \\
\hline Copper $(\mathrm{ppm})$ & $2.42(0.4)$ & $21.68(2.6)$ & $<0.001$ \\
\hline Percent organic matter & $3.46(0.57)$ & $4.9(1.07)$ & 0.029 \\
\hline Sodium $(\mathrm{ppm})$ & $135.8(17.0)$ & $50.4(2.7)$ & $<0.001$ \\
\hline Nitrate $(\mathrm{ppm})$ & $0.0(0.0)$ & $0.6(0.51)$ & 0.060 \\
\hline Ammonium $(\mathrm{ppm})$ & $5.26(1.37)$ & $5.64(1.54)$ & 0.828 \\
\hline Percent Moisture & $34.24(4.64)$ & $17.82(4.08)$ & $<0.001$ \\
\hline Total-N $(\%)$ & $0.139(0.04)$ & $0.1888(0.05)$ & 0.107 \\
\hline Sulfur $(\mathrm{ppm})$ & $23.6(4.6)$ & $17.4(2.9)$ & 0.034 \\
\hline
\end{tabular}

PC1 and $13.9 \%$ for PC2) (Fig. 1). Numerous abiotic parameters had significantly explanatory value for changes in microbiome community structure across samples (Supplementary Table S2). Coastal site samples were associated with greater moisture content, sodium, phosphorus, and sulfur, while inland site samples were associated with greater potassium, calcium, magnesium, and copper (Fig. 1).

PERMANOVA using weighted UniFrac distances revealed significant clustering of microbial communities by sample type (rhizosphere versus bulk soil; $F=8.011, P=0.001$ ) and site (coastal versus inland; $F=43.227, P=0.001$ ), as well as their interaction ( $F=4.307, P=0.006)$. We therefore investigated further by dividing the dataset by site and found that rhizosphere and bulk soils significantly differed in community composition at both the coastal and the inland sites $(F=8.2951, P=0.001$; and $F=4.918, P=$ 0.005 , respectively), and differed in variability by PERMDISP at the coastal site $(F=10.73, P=0.002)$. We next subdivided the rhizosphere samples by ecotype. We found that site influenced community composition for both the coastal $(F=28.828, P=0.001)$ and inland ecotypes $(F=16.319, P=0.001)$. In addition, the coastal ecotype differed in variability between the two sites $(F=7.3244$, $P=0.013$ ). Next, we found that inland ecotype rhizospheres differed from bulk soil in community composition at both the coastal and inland sites $(F=6.2055, P=0.001$; and $F=5.2513, P=0.007$, respectively), and differed in variability at the coastal site $(F=$ $13.198, P=0.004)$. Similarly, coastal ecotype rhizospheres differed from bulk soil at both the coastal and inland sites $(F=10.474, P=$ 0.001 ; and $F=3.8461, P=0.004$, respectively). We also tested for differences between ecotypes at each site and found that coastal and inland ecotypes differed in community composition at the inland site $(F=3.279, P=0.006)$, but not at the coastal site $(F=1.6859$, $P=0.095)$. Finally, we tested for differences between genotypes (within each ecotype at each site) and found that genotypes did not differ in any instance (all $P>0.05$ ).

A principal coordinates analysis based on Jaccard (binary presence/ absence) distances found that two axes together captured $35.6 \%$ of the variation in the amplicon sequencing dataset (Fig. 1). As with the PCoA of weighted UniFrac distances, all measured soil variables except ammonium were significantly associated with differences in community structure (Supplementary Table S3), and primarily distinguished the coastal and inland sites along axis 1 (Fig. 1). As with weighted UniFrac distances (Fig. 1), PERMANOVA using Jaccard distances revealed that sites differed in community composition for both the coastal $(F=9.515, P=0.001)$ and inland ecotypes $(F=$ $8.612, P=0.001)$. In addition, the coastal ecotype differed in variability between the two sites $(F=4.677, P=0.032)$. We also tested for differences between ecotypes at each site. Coastal and inland ecotypes differed in community composition at both the inland site $(F=1.753$, $P=0.027)$ and the coastal site $(F=1.431, P=0.047)$. Finally, we found that rhizosphere and bulk soils significantly differed in community composition at the coastal $(F=2.060, P=0.001)$, but not the inland sites $(F=0.3189, P=0.099)$, and differed in variability by PERMDISP at the coastal site $(F=32.73, P=0.001)$.

Ecotypes differ in rhizosphere community composition and diversity at inland site. Across environments and ecotypes, we detected 14,869 OTUs spanning a breadth of phylogenetic diversity. Species richness, phylogenetic diversity, and Shannon diversity were all significantly higher for the inland ecotype than the coastal ecotype at the inland site, while ecotypes did not differ at the coastal site (Fig. 2). Similarly, all three alpha diversity metrics significantly differed between sites for the coastal ecotype, but not the inland ecotype. It should be noted, however, that differences in Shannon diversity were only significant when an extreme outlier (greater than three standard deviations from the ecotype/site mean) was excluded. 
Next, we compared microbial abundances between ecotypes at each site, and found that the two ecotypes exhibited very similar relative abundances of microbial taxa at the class level (Fig. 3). The two ecotypes did differ in the abundances of several highly abundant taxa, but only at the inland site. At the inland site, the inland ecotype had greater relative abundance of Cytophagia, Deltaproteobacteria, Gammaproteobacteria, and Verrucomicrobia, but lower relative abundance of Acidobacteria, than the coastal ecotype (Fig. 3). Genotypes within each ecotype did not differ in relative abundances of taxa at either the coastal or the inland site (Supplementary Fig. S2).

Each ecotype exhibited some of the same compositional shifts in microbial communities (relative to bulk soil) in both sites. At both the coastal and inland sites, the inland ecotype exhibited lower
A

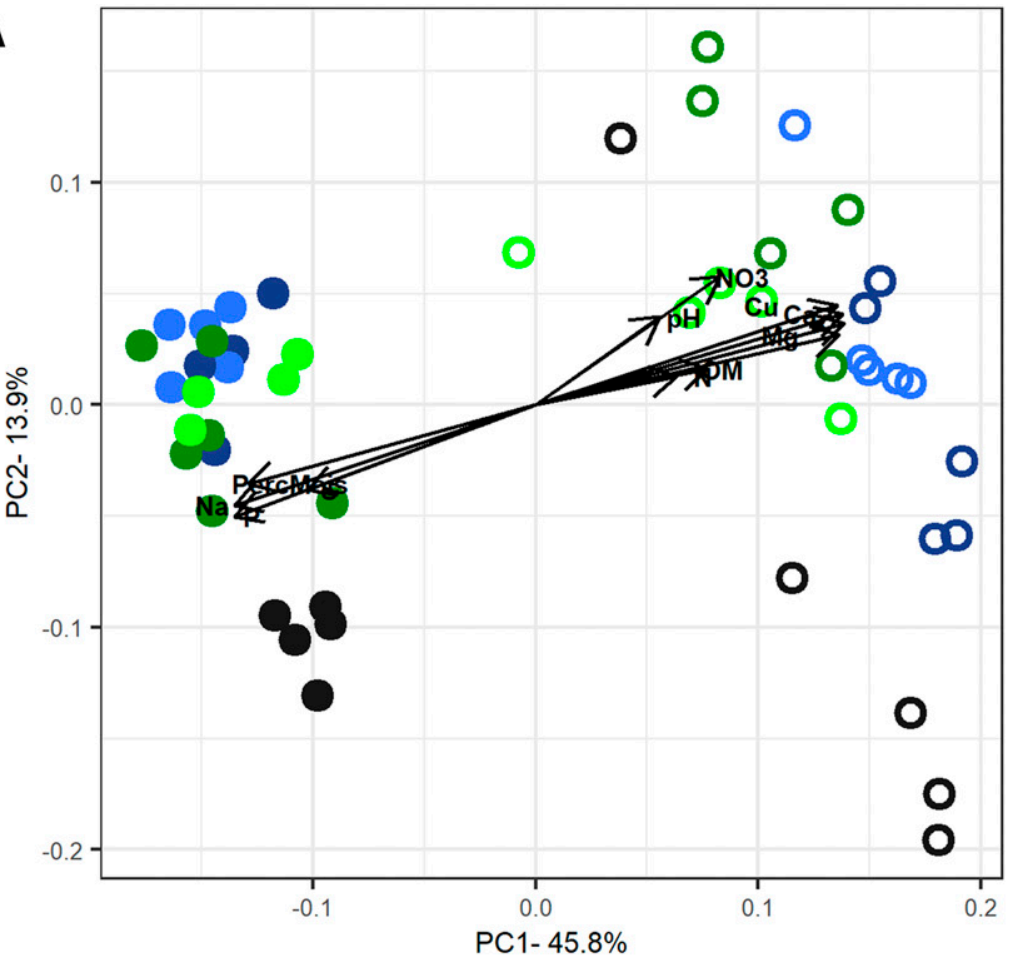

B

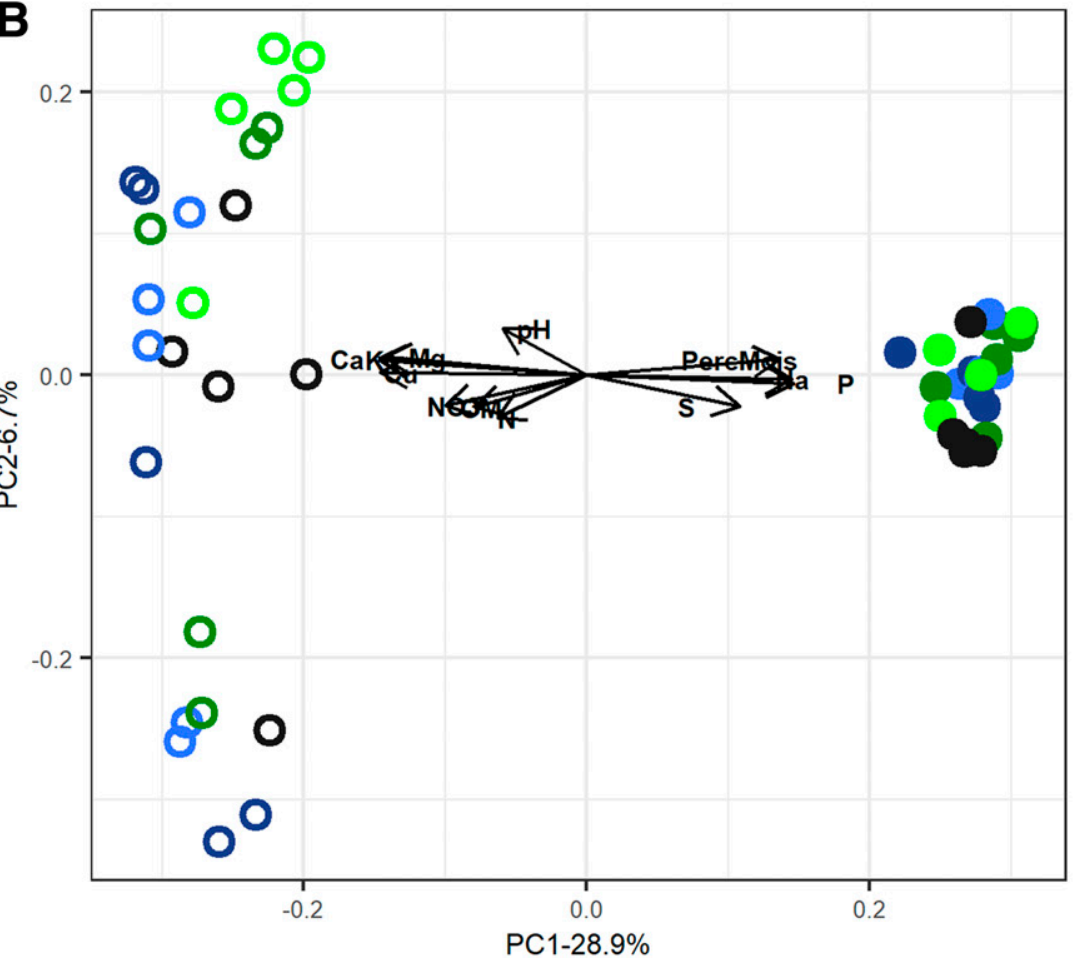

Coastal site

Bulk Soil

LMC (Inland ecotype)

OCC (Inland ecotype)

MRR (Coastal ecotype)

SWB (Coastal ecotype)

Inland site

( Bulk Soil

C LMC (Inland ecotype)

OCC (Inland ecotype)

O MRR (Coastal ecotype)

O SWB (Coastal ecotype)
Coastal site

Bulk Soil

LMC (Inland ecotype)

OCC (Inland ecotype)

MRR (Coastal ecotype)

SWB (Coastal ecotype)

Inland site

O Bulk Soil

- LMC (Inland ecotype)

OCC (Inland ecotype)

O MRR (Coastal ecotype)

- SWB (Coastal ecotype)

Fig. 1. Principal coordinates (PC) analysis based on A, weighted UniFrac distances and B, Jaccard distances of bacterial and archaeal community structure. The strength of statistically significant $(P<0.05)$ explanatory variables are shown with solid arrows. 
relative abundance of Acidobacteria, Gemmatimonadetes, and Nitrospira, and greater relative abundance of Planctomycetacia, compared with bulk soils (Supplementary Fig. S3). Similarly, at both sites, the coastal ecotype exhibited lower relative abundance of Nitrospira, and greater relative abundance of Planctomycetacia, compared with bulk soils. Within each site, both ecotypes influenced the relative abundance of numerous taxa in similar ways. At the coastal site, both ecotypes exhibited lower relative abundance of Acidobacteria, Anaerolineae, Gemmatimonadetes, Nitrospira, Deltaproteobacteria, and OPB35-Soil, and greater relative abundance of Thermoleophilia, Cytophagia, Sphingobacteria, KD4-96, Planctomycetacia, and Alpha-proteobacteria, compared with bulk soil. Similarly, at inland site, both ecotypes exhibited lower relative abundance of Nitrospira and greater relative abundance of Planctomycetacia compared with bulk soil. There were exceptions to this rule, however. For example, at the inland site, the inland ecotype exhibited lower relative abundance of Acidobacteria, Gemmatimonadetes, Spartobacteria, and greater relative abundance of Actinobacteria compared with bulk soil, while the coastal ecotype did not.

Presence/absence of microbial taxa differs between coastal and inland ecotypes. We next explored differences between ecotypes and sites at the individual OTU level. Indicator species analysis revealed that no bacterial species were indicative of coastal

\section{Coastal site}
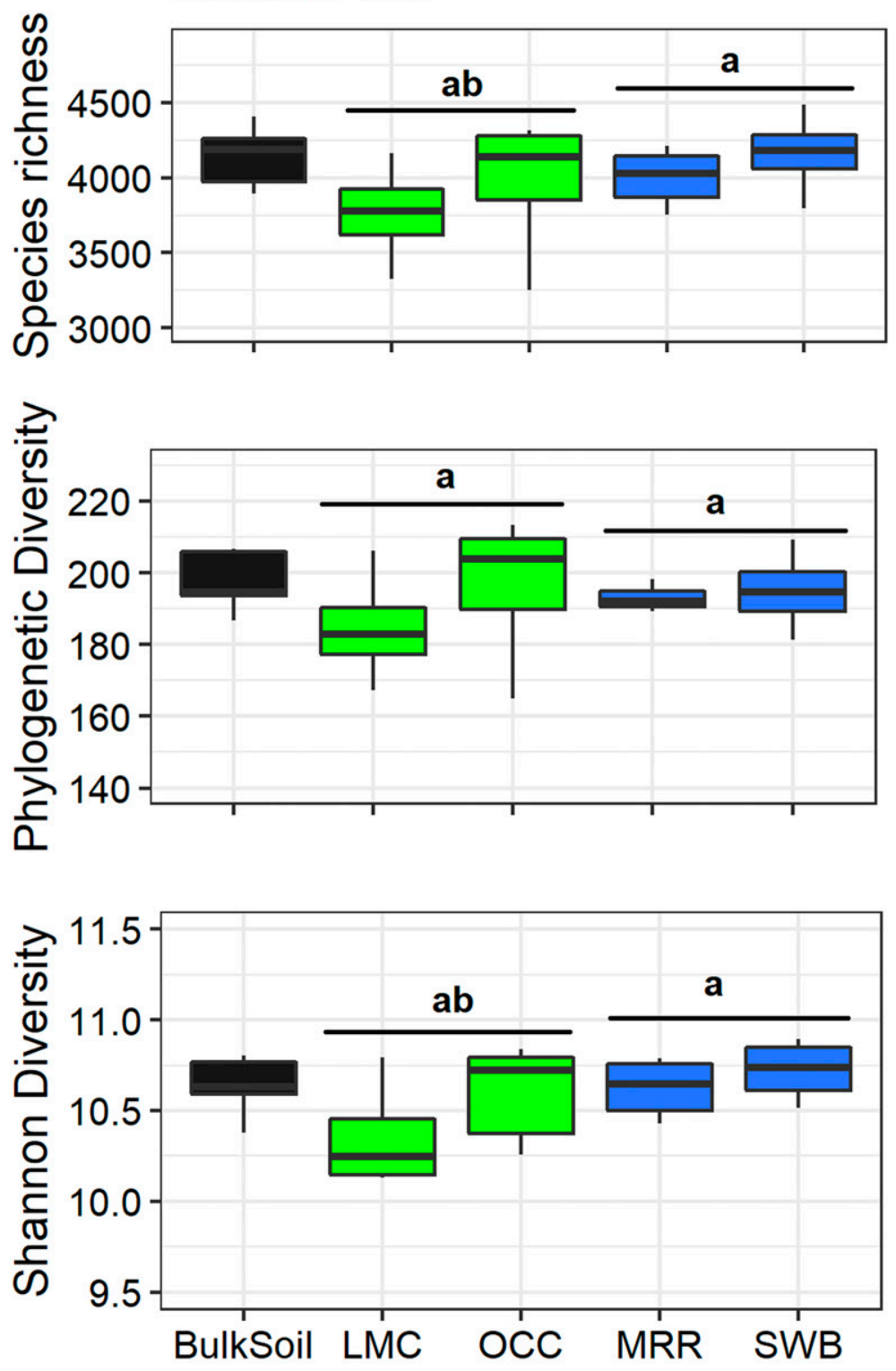

Inland site
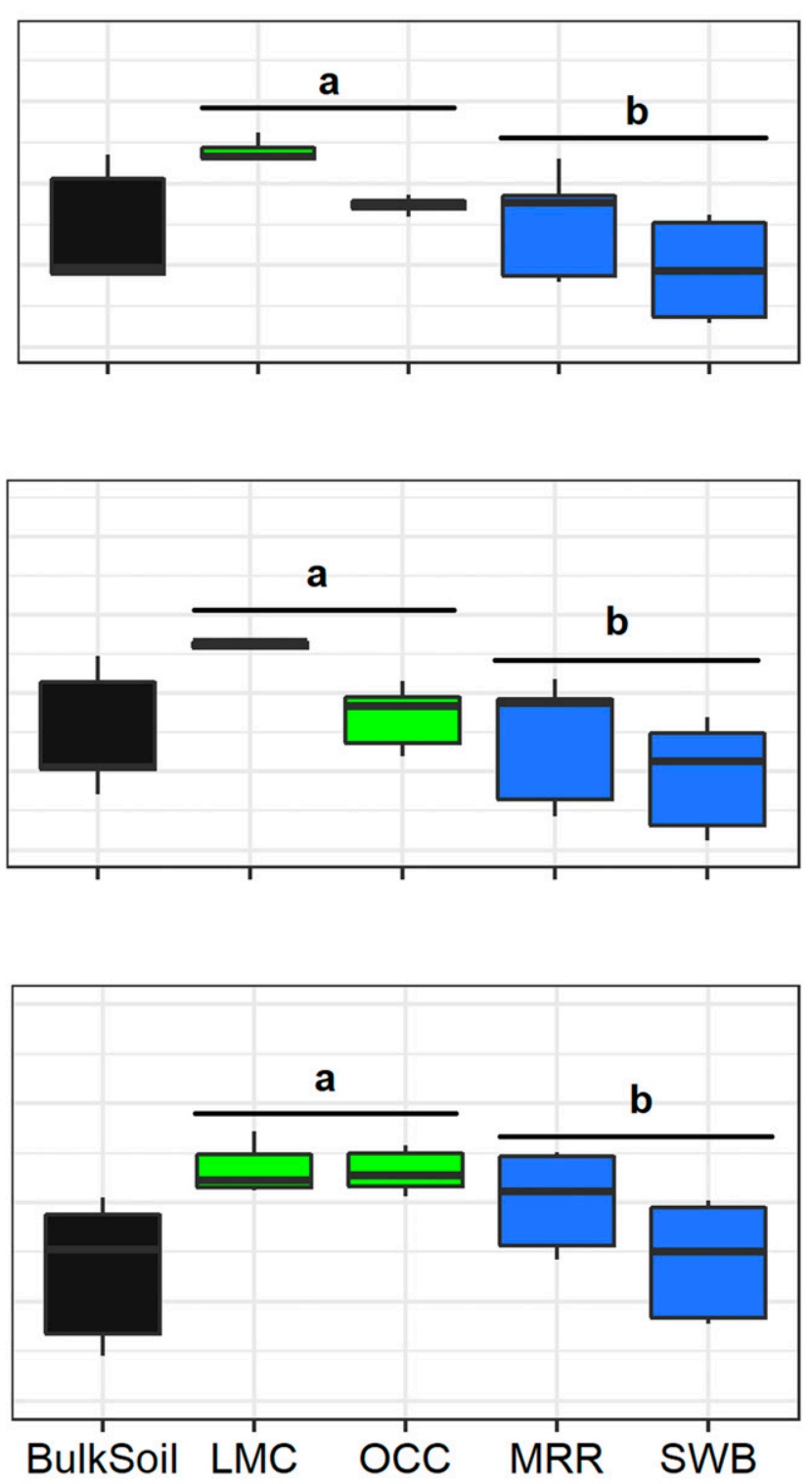

Bulk soil

Coastal ecotype

Inland ecotype

Fig. 2. Metrics of alpha diversity in bulk soil and rhizosphere of coastal (genotypes MRR and SWB pooled) and inland (genotypes LMC and OCC pooled) ecotypes of Mimulus guttatus planted in two environments. For each alpha diversity measure, ecotype-site combinations that significantly differed by the Tukey posthoc test are indicated by a different letter above the black lines. Note that differences in Shannon diversity were only significant when an extreme outlier (greater than three standard deviations from the mean) was excluded. Bulk soil values are shown for comparison. 
versus inland ecotypes at either the coastal or the inland site (all adjusted $P>0.05$ ). In addition, the coastal and inland ecotypes did not differ in relative abundance of any individual OTUs at either site. However, the two ecotypes did differ in the presence/absence of numerous OTUs at each site. At the inland site, 1,157 OTUs were present in the coastal but not the inland ecotype, while 2,065 OTUs were present in the inland but not the coastal ecotype (Fig. 4). Similarly, at the coastal site, 1,413 OTUs were present in the coastal but not the inland ecotype, while 1,395 OTUs were present in the inland but not the coastal ecotype (Fig. 4). At each site, these OTUs were in extremely low relative abundance (roughly 10-fold lower mean relative abundance) compared with the OTUs shared by the ecotypes and bulk soil. The OTUs distinguishing the ecotypes at each site also had very low occupancy (i.e., were present in a small proportion of samples per ecotype). For example, at the inland site, only 14 of the 1,157 OTUs unique to the coastal ecotype were present in at least half of the coastal ecotype samples, while only 99 of the 2,065 OTUs unique to the inland ecotype were present in at least half of the inland ecotype samples. Similarly, at the coastal site, only 39 of the 1,413 OTUs unique to the coastal ecotype were present in at least half of the coastal ecotype samples, while only 39 of the 1,395 OTUs unique to the inland ecotype were present in at least half of the inland ecotype samples. At both sites, a large number of OTUs were found in rhizosphere samples, but not the bulk soil, and vice versa (Fig. 4).

\section{DISCUSSION}

Interactions between plant roots and soil microorganisms strongly influence plant health and productivity, yet the relative role of host plant identity versus the local environment in shaping the rhizosphere microbiome is not well understood. To begin to unravel this, we examined the rhizosphere communities of two ecotypes of M. guttatus, which are locally adapted to distinct environments, in a reciprocal transplant experiment.

The local environment (coastal versus inland site) strongly influenced rhizosphere microbial communities in $M$. guttatus. This effect is due, at least in part, to distinct microbial source pools in the bulk soil at each site. This finding was not surprising given that abiotic conditions strongly differed between the two sites, and microbial community structure is often influenced by environmental gradients (Fierer et al. 2012; Lauber et al. 2009; Sorensen et al. 2019; Xue et al. 2018). For example, both salinity (Rath et al. 2019) and moisture availability (Brockett et al. 2012), two of the major factors distinguishing the coastal and inland sites, can have substantial effects on microbial community structure. Indeed, numerous abiotic factors had significant explanatory value for the differences in microbial community structure across samples. In particular, the sharp differences between microbial communities at the coastal and inland sites were related to differences in nutrient availability, salinity, and moisture between the sites.

Host plant identity also influenced rhizosphere community composition in $M$. guttatus, but to a smaller extent than the influence of environment. At each site, the two ecotypes exhibited remarkably similar abundances of microbial taxa at the Class level. Many of the shared lineages are commonly associated with rhizospheres, including Actinobacteria, Firmicutes, Alpha- and Betaproteobacteria (Philippot et al. 2013), suggesting evolutionarilyconserved mechanisms for recruiting and/or sustaining these taxa. Our results indicate that divergent $M$. guttatus ecotypes recruit phylogenetically similar rhizosphere communities, even in environments to which they are maladapted. Nevertheless, the ecotypes differed in community composition at the inland site when considering weighted UniFrac distances (phylogenetic distance weighted by taxon relative abundance), and differed at both the coastal and inland sites when considering Jaccard distances (presence/absence of microbial OTUs). At both sites, numerous taxa of low abundance (rare) and low occupancy (found in a low proportion of samples) were found in one ecotype at the exclusion of the other, supporting the differences between ecotypes detected using Jaccard distances. Although the rarity of these OTUs suggests they may be present in the $M$. guttatus rhizosphere due to stochastic processes rather than deterministic recruitment by the plant host, rare microbial taxa have the potential to provide a reservoir of microbial functions that can support community stability despite environmental fluctuations (Shade and Gilbert 2015; Shade et al.
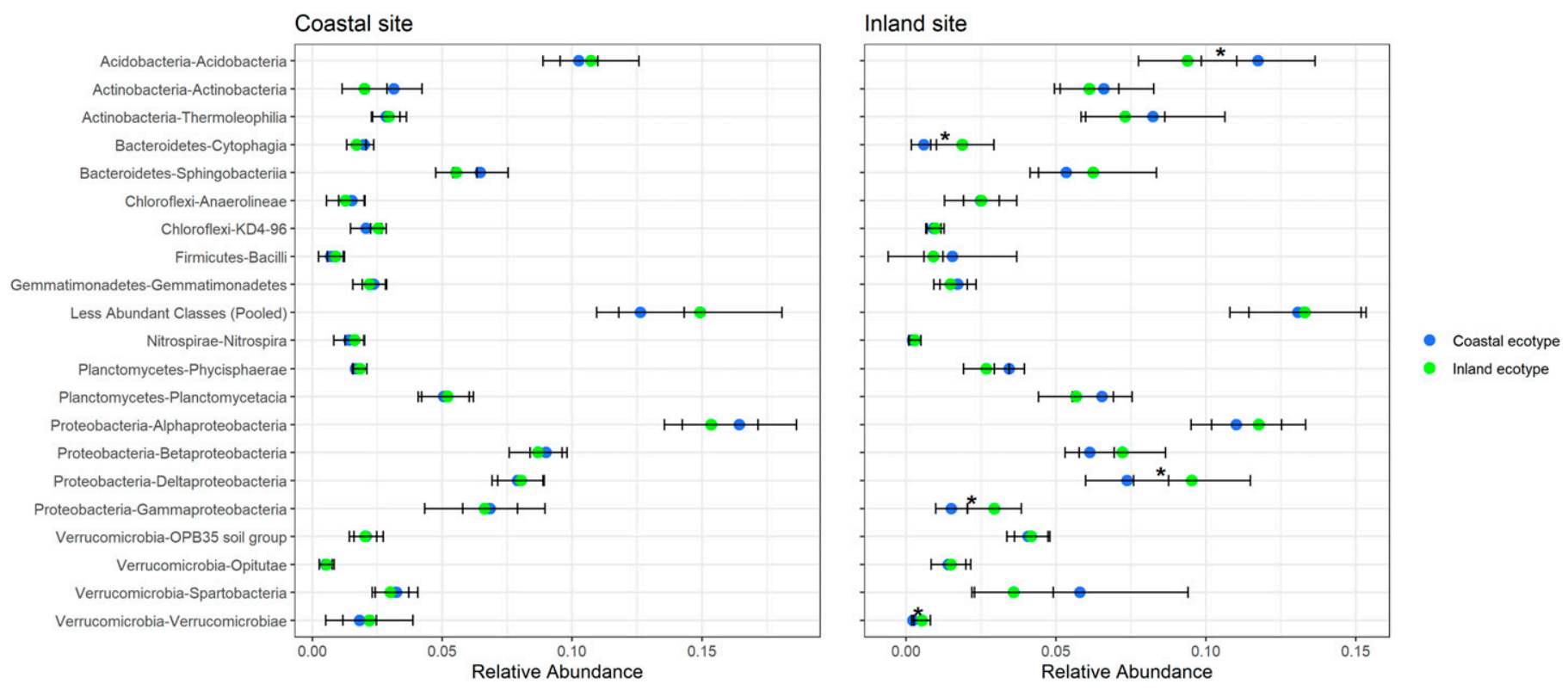

Fig. 3. Relative abundance (mean \pm SD) of the top 20 most abundant bacterial and archaeal classes in the rhizospheres of coastal (genotypes MRR and SWB pooled) and inland (genotypes LMC and OCC pooled) ecotypes of Mimulus guttatus planted in two environments. Less abundant taxa were pooled into a single group (Less Abundant Classes). Taxa that significantly differed between ecotypes at a given site are indicated by an asterisk. 
2014). The design of the present study does not allow us to determine whether differing rhizosphere communities are a cause or a consequence of the evolutionary divergence between the ecotypes, nor does it allow us to assess the biological relevance (if any) of the rare microbial taxa detected here. Future work could explore the potential role of the rhizosphere microbiome in local adaptation in this system by examining growth and fitness of the two ecotypes in sterilized and unsterilized 'home' and 'away' soil. For this type of experiment, a greater difference in fitness between the two ecotypes in the unsterilized soil would indicate that soil microbial communities contribute to local adaptation and ecotypic divergence in

\section{Inland Site}

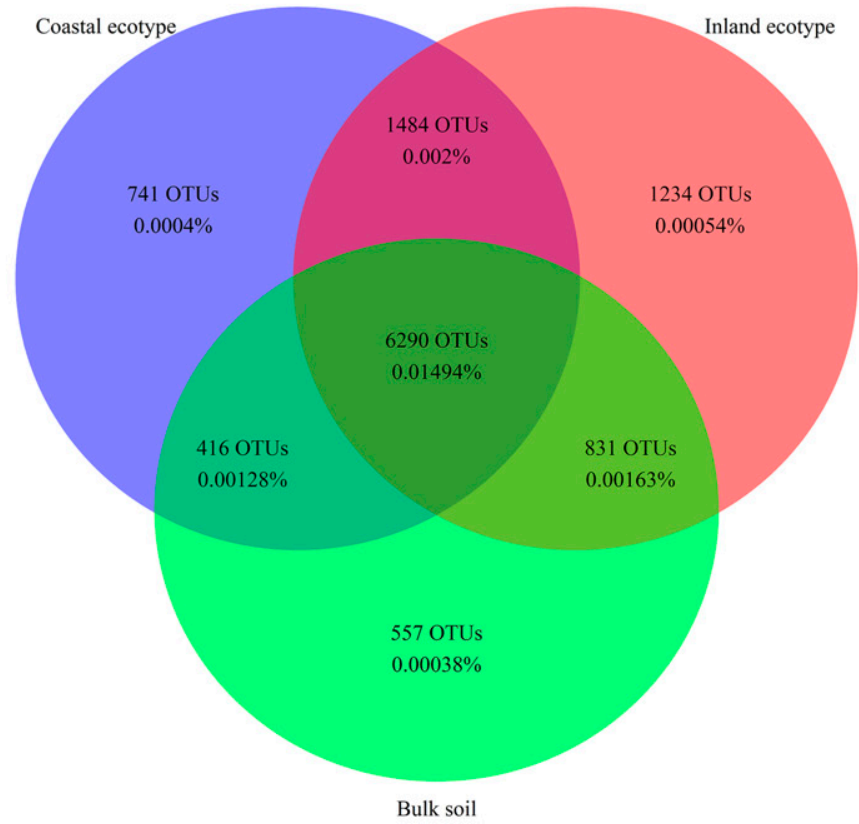

Coastal Site

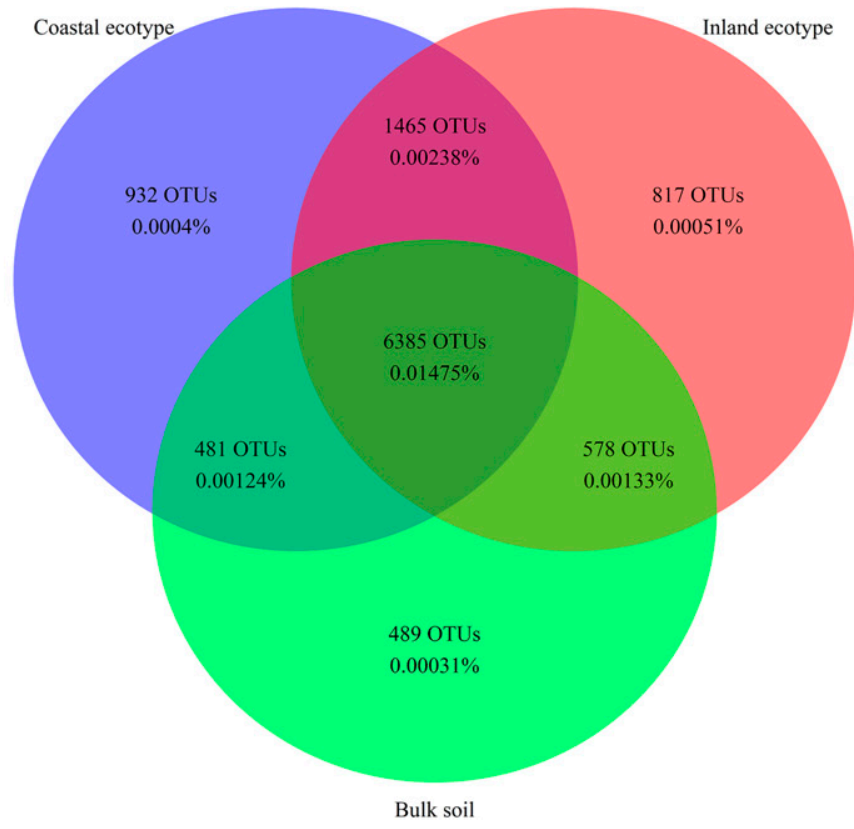

Fig. 4. Presence and relative abundance of microbial operational taxonomic units (OTUs) in each ecotype rhizosphere and bulk soil at the inland and coastal sites. Labels indicate the number of OTUs unique to a given set, as well as the mean relative abundance of those OTUs across the full dataset.
M. guttatus. Such experiments could be conducted in controlled greenhouse conditions to specifically isolate the effects of soil communities on plant fitness, rather than environmental factors such as oceanic salt spray and drought which strongly impact M. guttatus fitness in the field (Lowry et al. 2008, 2009; Popovic and Lowry, in press).

Our finding that plant host identity impacts rhizosphere communities in both common garden sites strongly suggests that the M. guttatus ecotypes are genetically diverged in the factors shaping those communities. Although numerous studies have documented genetic differentiation for rhizosphere microbiome communities in crops and model species in controlled environments (Aira et al. 2010; Costa et al. 2006; Mahoney et al. 2017; Micallef et al. 2009; Peiffer et al. 2013), our work is one of only a few studies reporting genotype-specific effects of wild plants in natural environments (Aleklett et al. 2015; Kuske et al. 2002; Osanai et al. 2013). Our study differs in that it used seedlings germinated in a common controlled environment, and then transplanted to natural environments for a portion of the growing season, rather than sampling from established plant communities as in previous work of wild plants (Aleklett et al. 2015; Kuske et al. 2002; Osanai et al. 2013). We hypothesize that variable root exudate composition and/or root morphology between $M$. guttatus ecotypes acts to differentially shape rhizosphere community structure in these ecotypes.

Interestingly, the effect of host plant identity reported here was environment-dependent: the two ecotypes only differed in alpha diversity at the inland site. The ability of the inland ecotype to harbor a more OTU-rich and phylogenetically diverse rhizosphere could potentially contribute to its greater fitness at the inland site compared with the coastal ecotype. Previous work in the $M$. guttatus system has found that the coastal ecotype exhibits extremely low fitness in inland sites due to near-zero survival-toflowering rates (Lowry and Willis 2010; Lowry et al. 2008). Although the sample collections made here were completed before the inland site dried out for the summer (and the ecotypes did not differ in biomass at the inland site), it is possible that the early stages of physiological stress at the inland environment contributed to the differences in rhizosphere composition between the two ecotypes seen here. In any case, the complex interplay between host identity and environment is consistent with the contrasting results seen in studies of cultivated crops. For example, some studies report that differences in rhizosphere community composition across species or genotypes are environment-dependent (Costa et al. 2006; Marschner et al. 2004; Peiffer et al. 2013), while others find that differences across species or genotypes are maintained regardless of environment (Mahoney et al. 2017; Marschner et al. 2001). Although the two ecotypes are indeed genetically diverged in factors shaping the rhizosphere microbiome, environmental factors can outweigh genetic factors in shaping the $M$. guttatus microbiome at least for the field sites examined in our study.

It is worth noting that numerous taxa were detected in the M. guttatus rhizosphere that were not detected in bulk soil. For example, rhizosphere and bulk soil communities differed at both coastal and inland sites, suggesting the presence of $M$. guttatus strongly influences soil microbiome structure. An important caveat of this finding is that the horticultural potting soil in which the seedlings were germinated likely contributed to the differences between rhizosphere and bulk communities detected here, thought we suggest that this influence was minimal given that care was taken to not transplant notable amounts of potting soil. We suggest that the differences between rhizosphere and bulk communities at both sites was not solely an artifact of the germination media, given the general observation that plants play a major role in regulating soil microbial community composition and function (reviewed in 
Bulgarelli et al. [2013]; Coskun et al. [2017]; Lareen et al. [2016]). In any case, our study was primarily designed to assess the relative roles of host plant identity and the local environment in shaping the rhizosphere microbiome, which were detectable in spite of the common germination environment.

In summary, we found that the local environment (coastal versus inland site) strongly influenced rhizosphere communities, at least in part due to distinct composition of the microbial source pool at each site. Although host plant identity also influenced rhizosphere community composition, it was to a much smaller extent than the influence of the environment. At each site, the two ecotypes exhibited remarkably similar abundances of microbial taxa at the Class level, indicating that divergent $M$. guttatus ecotypes recruit phylogenetically similar rhizosphere communities, even in foreign habitats. Nevertheless, the two ecotypes did differ in rhizosphere community composition at both sites, due, at least in part, to differences in the presence or absence of microbial taxa, particularly rare (low abundance and low occupancy) taxa. In addition, the ecotypes differed in alpha diversity at the inland site, but not the coastal site. This indicates an element of environment-dependence in the plant genetic factors that regulate the M. guttatus microbiome, and highlights the context-specific interactions between host identity and local environment in shaping those communities.

\section{ACKNOWLEDGMENTS}

We thank Benjamin Blackman, Erin Patterson, and the University of California Berkeley greenhouse staff for maintaining our seedlings prior to this experiment and Daniel Jackson for assisting with the fieldwork. We are grateful to the Pepperwood Preserve and University of California, Davis Bodega Marine Reserve for permission to conduct our experiments at these locations. We would especially like to thank Michelle Halbur and Michael Gillogly (Pepperwood) as well as Jacqueline Sones (Bodega) for helping to facilitate our research. The Department of Parks and Recreation of the State of California provided permission to make seed collections for this experiment.

\section{LITERATURE CITED}

Aira, M., Gómez-Brandón, M., Lazcano, C., Bååth, E., and Domínguez, J. 2010. Plant genotype strongly modifies the structure and growth of maize rhizosphere microbial communities. Soil Biol. Biochem. 42:2276-2281.

Aleklett, K., Leff, J. W., Fierer, N., and Hart, M. 2015. Wild plant species growing closely connected in a subalpine meadow host distinct rootassociated bacterial communities. PeerJ 3:e804.

Anderson, M. J. 2006. Distance-based tests for homogeneity of multivariate dispersions. Biometrics 62:245-253.

Anderson, M. J. M. J. 2001. A new method for non-parametric multivariate analysis of variance. Austral. Ecol. 26:32-46.

Angers, D. A., and Caron, J. 1998. Plant-induced changes in soil structure: Processes and feedbacks. Biogeochemistry 42:55-72.

Baptiste, A. 2017. gridExtra: Miscellaneous functions for "Grid" graphics. $\mathrm{R}$ package version 2.3. https://cran.r-project.org/web/packages/gridExtra/ gridExtra.pdf

Berendsen, R. L., Pieterse, C. M. J., and Bakker, P. A. H. M. 2012. The rhizosphere microbiome and plant health. Trends Plant Sci. 17:478-486.

Berg, G., Roskot, N., Steidle, A., Eberl, L., Zock, A., and Smalla, K. 2002. Plantdependent genotypic and phenotypic diversity of antagonistic rhizobacteria isolated from different Verticillium host plants. Appl. Environ. Microbiol. 68: 3328-3338.

Berg, G., and Smalla, K. 2009. Plant species and soil type cooperatively shape the structure and function of microbial communities in the rhizosphere. FEMS Microbiol. Ecol. 68:1-13.

Bever, J. D., Platt, T. G., and Morton, E. R. 2012. Microbial population and community dynamics on plant roots and their feedbacks on plant communities. Annu. Rev. Microbiol. 66:265-283.
Bouffaud, M. L., Kyselková, M., Gouesnard, B., Grundmann, G., Muller, D., and Moënne-Loccoz, Y. 2012. Is diversification history of maize influencing selection of soil bacteria by roots? Mol. Ecol. 21:195-206.

Bowen, J. L., Kearns, P. J., Byrnes, J. E. K., Wigginton, S., Allen, W. J., Greenwood, M., Tran, K., Yu, J., Cronin, J. T., and Meyerson, L. A. 2017. Lineage overwhelms environmental conditions in determining rhizosphere bacterial community structure in a cosmopolitan invasive plant. Nat. Commun. 8:433.

Bressan, M., Roncato, M.-A., Bellvert, F., Comte, G., Haichar, F. Z., Achouak, W., and Berge, O. 2009. Exogenous glucosinolate produced by Arabidopsis thaliana has an impact on microbes in the rhizosphere and plant roots. ISME J. 3:1243-1257.

Brockett, B. F. T., Prescott, C. E., and Grayston, S. J. 2012. Soil moisture is the major factor influencing microbial community structure and enzyme activities across seven biogeoclimatic zones in western Canada. Soil Biol. Biochem. 44: 9-20.

Broeckling, C. D., Broz, A. K., Bergelson, J., Manter, D. K., and Vivanco, J. M. 2008. Root exudates regulate soil fungal community composition and diversity. Appl. Environ. Microbiol. 74:738-744.

Bulgarelli, D., Rott, M., Schlaeppi, K., Ver Loren van Themaat, E., Ahmadinejad, N., Assenza, F., Rauf, P., Huettel, B., Reinhardt, R., Schmelzer, E., Peplies, J., Gloeckner, F. O., Amann, R., Eickhorst, T., and Schulze-Lefert, P. 2012. Revealing structure and assembly cues for Arabidopsis root-inhabiting bacterial microbiota. Nature 488:91-95.

Bulgarelli, D., Schlaeppi, K., Spaepen, S., Ver Loren van Themaat, E., and Schulze-Lefert, P. 2013. Structure and functions of the bacterial microbiota of plants. Annu. Rev. Plant Biol. 64:807-838.

Busby, P. E., Peay, K. G., and Newcombe, G. 2016. Common foliar fungi of Populus trichocarpa modify Melampsora rust disease severity. New Phytol. 209:1681-1692.

Caporaso, J. G., Kuczynski, J., Stombaugh, J., Bittinger, K., Bushman, F. D., Costello, E. K., Fierer, N., Peña, A. G., Goodrich, J. K., Gordon, J. I., Huttley, G. A., Kelley, S. T., Knights, D., Koenig, J. E., Ley, R. E., Lozupone, C. A., McDonald, D., Muegge, B. D., Pirrung, M., Reeder, J., Sevinsky, J. R., Turnbaugh, P. J., Walters, W. A., Widmann, J., Yatsunenko, T., Zaneveld, J., and Knight, R. 2010. QIIME allows analysis of high-throughput community sequencing data. Nat. Methods 7:335-336.

Carvalhais, L. C., Dennis, P. G., Badri, D. V., Kidd, B. N., Vivanco, J. M., and Schenk, P. M. 2015. Linking jasmonic acid signaling, root exudates, and rhizosphere microbiomes. Mol. Plant-Microbe Interact. 28:1049-1058.

Carvalhais, L. C., Dennis, P. G., Fedoseyenko, D., Hajirezaei, M.-R., Borriss, R., and Von Wirén, N. 2011. Root exudation of sugars, amino acids, and organic acids by maize as affected by nitrogen, phosphorus, potassium, and iron deficiency. J. Plant Nutr. Soil Sci. 174:3-11.

Chaparro, J. M., Badri, D. V., and Vivanco, J. M. 2014. Rhizosphere microbiome assemblage is affected by plant development. ISME J. 8:790-803.

Chen, H. 2018. VennDiagram: Generate high-resolution Venn and Euler plots. R package version 1.6.20. https://cran.r-project.org/web/packages/ VennDiagram/VennDiagram.pdf

Coskun, D., Britto, D. T., Shi, W., and Kronzucker, H. J. 2017. How plant root exudates shape the nitrogen cycle. Trends Plant Sci. 22:661-673.

Costa, R., Götz, M., Mrotzek, N., Lottmann, J., Berg, G., and Smalla, K. 2006. Effects of site and plant species on rhizosphere community structure as revealed by molecular analysis of microbial guilds. FEMS Microbiol. Ecol. 56:236-249.

De Cáceres, M., and Legendre, P. 2009. Associations between species and groups of sites: Indices and statistical inference. Ecology 90:3566-3574.

De Cáceres, M., Legendre, P., and Moretti, M. 2010. Improving indicator species analysis by combining groups of sites. Oikos 119:1674-1684. https:// www.jstor.org/stable/20779094

Edgar, R. C. 2004. MUSCLE: Multiple sequence alignment with high accuracy and high throughput. Nucleic Acids Res. 32:1792-1797.

Edgar, R. C. 2010. Search and clustering orders of magnitude faster than BLAST. Bioinformatics 26:2460-2461.

Edgar, R. C. 2016. UNOISE2: Improved error-correction for Illumina $16 \mathrm{~S}$ and ITS amplicon sequencing. bioRxiv 081257

Edwards, J., Johnson, C., Santos-Medellín, C., Lurie, E., Podishetty, N. K., Bhatnagar, S., Eisen, J. A., and Sundaresan, V. 2015. Structure, variation, and assembly of the root-associated microbiomes of rice. Proc. Natl. Acad. Sci. 112:E911-E920.

Fierer, N., and Jackson, R. B. 2006. The diversity and biogeography of soil bacterial communities. Proc. Natl. Acad. Sci. USA 103:626-631.

Fierer, N., Lauber, C. L., Ramirez, K. S., Zaneveld, J., Bradford, M. A., and Knight, R. 2012. Comparative metagenomic, phylogenetic and physiological 
analyses of soil microbial communities across nitrogen gradients. ISME J. 6: 1007-1017.

Fierer, N., Schimel, J. P., and Holden, P. A. 2003. Variations in microbial community composition through two soil depth profiles. Soil Biol. Biochem. 35:167-176

Fitzpatrick, C. R., Copeland, J., Wang, P. W., Guttman, D. S., Kotanen, P. M., and Johnson, M. T. J. 2018. Assembly and ecological function of the root microbiome across angiosperm plant species. Proc. Natl. Acad. Sci. 115: E1157-E1165.

Fox, J., and Weisberg, S. 2011. An R Companion to Applied Regression, 2nd ed. Sage, Thousand Oaks, CA.

Friesen, M. L., Porter, S. S., Stark, S. C., von Wettberg, E. J., Sachs, J. L., and Martinez-Romero, E. 2011. Microbially mediated plant functional traits. Annu. Rev. Ecol. Evol. Syst. 42:23-46.

Gargallo-Garriga, A., Preece, C., Sardans, J., Oravec, M., Urban, O., and Peñuelas, J. 2018. Root exudate metabolomes change under drought and show limited capacity for recovery. Nat. Sci. Rep. 8:1-15.

Gu, Y., Wei, Z., Wang, X., Friman, V. P., Huang, J., Wang, X., Mei, X., Xu, Y., Shen, Q., and Jousset, A. 2016. Pathogen invasion indirectly changes the composition of soil microbiome via shifts in root exudation profile. Biol. Fertil. Soils 52:997-1005.

Haichar, F. Z., Marol, C., Berge, O., Rangel-Castro, J. I., Prosser, J. I., Balesdent, J., Heulin, T., and Achouak, W. 2008. Plant host habitat and root exudates shape soil bacterial community structure. ISME J. 2:1221-1230.

Hall, M. C., Lowry, D. B., and Willis, J. H. 2010. Is local adaptation in Mimulus guttatus caused by trade-offs at individual loci? Mol. Ecol. 19:2739-2753.

Hall, M. C., and Willis, J. H. 2006. Divergent selection on flowering time contributes to local adaptation in Mimulus guttatus populations. Evolution (N. Y.) 60:2466-2477

Henry, A., Doucette, W., Norton, J., and Bugbee, B. 2007. Changes in crested wheatgrass root exudation caused by flood, drought, and nutrient stress. J. Environ. Qual. 36:904-912.

Hu, L., Robert, C. A. M., Cadot, S., Zhang, X., Ye, M., Li, B., Manzo, D., Chervet, N., Steinger, T., Van Der Heijden, M. G. A., Schlaeppi, K., and Erb, M. 2018. Root exudate metabolites drive plant-soil feedbacks on growth and defense by shaping the rhizosphere microbiota. Nat. Commun. 9:2738.

Jaccard, P. 1901. Distribution de la flore alpine dans le bassin des Dranses et dans quelques regions voisines. Bull. Soc. Vaud. Sci. Nat. 37:547-579.

Kiba, T., and Krapp, A. 2016. Plant nitrogen acquisition under low availability: Regulation of uptake and root architecture. Plant Cell Physiol. 57:707-714.

Kjeldahl, J. 1883. New method for the determination of nitrogen in organic substances. Z. Anal. Chem. 22:366-383.

Ko, D., Yoo, G., Yun, S.-T., Jun, S.-C., and Chung, H. 2017. Bacterial and fungal community composition across the soil depth profiles in a fallow field. J. Ecol. Environ. 41:1-10.

Kozich, J. J., Westcott, S. L., Baxter, N. T., Highlander, S. K., and Schloss, P. D. 2013. Development of a dual-index sequencing strategy and curation pipeline for analyzing amplicon sequence data on the MiSeq Illumina sequencing platform. Appl. Environ. Microbiol. 79:5112-5120.

Kuske, C. R., Ticknor, L. O., Miller, M. E., Dunbar, J. M., Davis, J. A., Barns, S. M., and Belnap, J. 2002. Comparison of soil bacterial communities in rhizospheres of three plant species and the interspaces in an arid grassland. Appl. Environ. Microbiol. 68:1854-1863.

Lareen, A., Burton, F., and Schäfer, P. 2016. Plant root-microbe communication in shaping root microbiomes. Plant Mol. Biol. 90:575-587.

Lau, J. A., and Lennon, J. T. 2011. Evolutionary ecology of plant-microbe interactions: Soil microbial structure alters selection on plant traits. New Phytol. 192:215-224.

Lau, J. A., and Lennon, J. T. 2012. Rapid responses of soil microorganisms improve plant fitness in novel environments. Proc. Natl. Acad. Sci. USA 109: 14058-14062.

Lauber, C. L., Hamady, M., Knight, R., and Fierer, N. 2009. Pyrosequencingbased assessment of soil $\mathrm{pH}$ as a predictor of soil bacterial community structure at the continental scale. Appl. Environ. Microbiol. 75:5111-5120.

Levene, H. 1960. Robust tests for equality of variances. Pages 278-292 in: Contributions to Probability and Statistics: Essays in Honor of Harold Hotelling. I. Olkin, S. G. Ghurye, W. Hoeffding, W. G. Madow, and H. B. Mann, eds. Stanford University Press, Palo Alto, CA.

Lopez-Bucio, J., Cruz-Ramirez, A., and Herrera-Estrella, L. 2003. The role of nutrient availability in regulating root architecture. Curr. Opin. Plant Biol. 6: 280-287.

Lowry, D. B., Hall, M. C., Salt, D. E., and Willis, J. H. 2009. Genetic and physiological basis of adaptive salt tolerance divergence between coastal and inland Mimulus guttatus. New Phytol. 183:776-788.
Lowry, D. B., Rockwood, R. C., and Willis, J. H. 2008. Ecological reproductive isolation of coast and inland races of Mimulus guttatus. Evolution (N.Y.) 62: 2196-2214.

Lowry, D. B., and Willis, J. H. 2010. A widespread chromosomal inversion polymorphism contributes to a major life-history transition, local adaptation, and reproductive isolation. PLoS Biol. 8:e1000500.

Lozupone, C., and Knight, R. 2005. UniFrac: A new phylogenetic method for comparing microbial communities. Appl. Environ. Microbiol. 71: 8228-8235.

Mahoney, A. K., Yin, C., and Hulbert, S. H. 2017. Community structure, species variation, and potential functions of rhizosphere-associated bacteria of different winter wheat (Triticum aestivum) cultivars. Front. Plant Sci. 8:1-14.

Marschner, H., Romheld, V., and Cakmak, I. 1987. Root-induced changes of nutrient availability in the rhizosphere. J. Plant Nutr. 10:1175-1184.

Marschner, P., Crowley, D., and Yang, C. H. 2004. Development of specific rhizosphere bacterial communities in relation to plant species, nutrition and soil type. Plant Soil 261:199-208.

Marschner, P., Yang, C.-H., Lieberei, R., and Crowley, D. E. 2001. Soil and plant specific effects on bacterial community composition in the rhizosphere. Soil Biol. Biochem. 33:1437-1445.

Martin, M. 2011. Cutadapt removes adapter sequences from high-throughput sequencing reads. EMBnet.journal 17:10-12.

McDonald, D., Clemente, J. C., Kuczynski, J., Rideout, J. R., Stombaugh, J., Wendel, D., Wilke, A., Huse, S., Hufnagle, J., Meyer, F., Knight, R., and Caporaso, J. G. 2012. The Biological Observation Matrix (BIOM) format or: How I learned to stop worrying and love the ome-ome. Gigascience 1:7.

McKinney, J., and Cleland, E. E. 2014. Root inputs influence soil water holding capacity and differentially influence the growth of native versus exotic annual species in an arid ecosystem. Restor. Ecol. 22:766-773.

Micallef, S. A., Shiaris, M. P., and Colón-Carmona, A. 2009. Influence of Arabidopsis thaliana accessions on rhizobacterial communities and natural variation in root exudates. J. Exp. Bot. 60:1729-1742.

Niu, Y. F., Chai, R. S., Jinn, G. L., Wang, H., Tang, C., and Zhang, Y. S. 2013. Responses of root architecture development to low phosphorus availability: A review. Ann. Bot. 112:391-408.

Oksanen, J., Blanchet, F. G., Friendly, M., Kindt, R., Legendre, P., McGlinn, D., Minchin, P. R., O’Hara, R. B., Simpson, G. L., Solymos, P., Stevens, M. H. H., Szoecs, E., and Wagner, H. 2018. vegan: Community ecology package. R package version 2.5-2. https://CRAN.R-project.org/package=vegan

Osanai, Y., Bougoure, D. S., Hayden, H. L., and Hovenden, M. J. 2013. Cooccurring grass species differ in their associated microbial community composition in a temperate native grassland. Plant Soil 368:419-431.

Peiffer, J. A., Spor, A., Koren, O., Jin, Z., Tringe, S. G., Dangl, J. L., Buckler, E. S., and Ley, R. E. 2013. Diversity and heritability of the maize rhizosphere microbiome under field conditions. Proc. Natl. Acad. Sci. USA 110: 6548-6553.

Pérez-Jaramillo, J. E., Carrión, V. J., Bosse, M., Ferrão, L. F. V., De Hollander, M., Garcia, A. A. F., Ramírez, C. A., Mendes, R., and Raaijmakers, J. M. 2017. Linking rhizosphere microbiome composition of wild and domesticated Phaseolus vulgaris to genotypic and root phenotypic traits. ISME J. 11: 2244-2257.

Philippot, L., Raaijmakers, J. M., Lemanceau, P., and van der Putten, W. H. 2013. Going back to the roots: the microbial ecology of the rhizosphere. Nat. Rev. Microbiol. 11:789-799.

Popovic, D., and Lowry, D. Contrasting environmental factors drive local adaptation at opposite ends of an environmental gradient in the yellow monkeyflower (Mimulus guttatus). Am. J. Bot. (In press).

Price, M. N., Dehal, P. S., and Arkin, A. P. 2009. FastTree: Computing large minimum evolution trees with profiles instead of a distance matrix. Mol. Biol. Evol. 26:1641-1650.

Price, M. N., Dehal, P. S., and Arkin, A. P. 2010. FastTree 2-Approximately maximum-likelihood trees for large alignments. PLoS One 5:e9490.

Quast, C., Pruesse, E., Yilmaz, P., Gerken, J., Schweer, T., Yarza, P., Peplies, J. J., Glockner, F. O., and Glöckner, F. O. 2013. The SILVA ribosomal RNA gene database project: Improved data processing and web-based tools. Nucleic Acids Res. 41:590-596

R Core Team. 2018. R: A language and environment for statistical computing. R Foundation for Statistical Computing, Vienna, Austria.

Rath, K. M., Fierer, N., Murphy, D. V., and Rousk, J. 2019. Linking bacterial community composition to soil salinity along environmental gradients. ISME J. 13:836-846.

Ritpitakphong, U., Falquet, L., Vimoltust, A., Berger, A., Métraux, J. P., and L'Haridon, F. 2016. The microbiome of the leaf surface of Arabidopsis protects against a fungal pathogen. New Phytol. 210:1033-1043. 
Santhanam, R., Luu, V. T., Weinhold, A., Goldberg, J., Oh, Y., and Baldwin, I. T. 2015. Native root-associated bacteria rescue a plant from a sudden wilt disease that emerged during continuous cropping. Proc. Natl. Acad. Sci. 112:E5013-E5020.

Sasse, J., Martinoia, E., and Northen, T. 2018. Feed your friends: Do plant exudates shape the root microbiome? Trends Plant Sci. 23:25-41.

Shade, A., and Gilbert, J. A. 2015. Temporal patterns of rarity provide a more complete view of microbial diversity. Trends Microbiol. 23:335-340.

Shade, A., Gilbert, J. A., Knight, R., Fierer, N., Caporaso, J. G., Handelsman, J., and Jones, S. E. 2014. Conditionally rare taxa disproportionately contribute to temporal changes in microbial diversity. MBio 5:e01371-e14.

Snedecor, G., and Cochran, W. 1989. Statistical Methods, 8th ed. Iowa State University Press, Ames, IA.

Sorensen, J. W., Dunivin, T. K., Tobin, T. C., and Shade, A. 2019. Ecological selection for small microbial genomes along a temperate-to-thermal soil gradient. Nat. Microbiol. 4:55-61.

Twyford, A. D., Streisfeld, M. A., Lowry, D. B., and Friedman, J. 2015. Genomic studies on the nature of species: Adaptation and speciation in Mimulus. Mol. Ecol. 24:2601-2609.

Wagner, M. R., Lundberg, D. S., Coleman-Derr, D., Tringe, S. G., Dangl, J. L., and Mitchell-Olds, T. 2014. Natural soil microbes alter flowering phenology and the intensity of selection on flowering time in a wild Arabidopsis relative. Ecol. Lett. 17:717-726.

Warnes, G. R., Bolker, B., Bonebakker, L., Gentleman, R., Huber, W., Liaw, A., Lumley, T., Maechler, M., Magnusson, A., Moeller, S., Schwartz, M., and
Venables, B. 2019. gplots: Various R programming tools for plotting data. $\mathrm{R}$ package version 3.0.1.1. https://CRAN.R-project.org/package=gplots

Wickham, H. 2007. Reshaping data with the reshape package. J. Stat. Softw. 21: $1-20$.

Wickham, H. 2009. ggplot2: Elegant graphics for data analysis. Springer-Verlag, New York.

Wickham, H. 2011. The split-apply-combine strategy for data analysis. J. Stat. Softw. 40:1-29.

Wilke, C. O. 2017. cowplot: Streamlined plot theme and plot annotations for "ggplot2". R package version 0.9.2. https://wilkelab.org/cowplot

Wu, C. A., Lowry, D. B., Cooley, A. M., Wright, K. M., Lee, Y. W., and Willis, J. H. 2008. Mimulus is an emerging model system for the integration of ecological and genomic studies. Heredity 100:220-230.

Xue, P., Carrillo, Y., Pino, V., Minasny, B., and McBratney, A. B. 2018. Soil properties drive microbial community structure in a large scale transect in south eastern Australia. Sci. Rep. 8:11725.

Zhalnina, K., Louie, K. B., Hao, Z., Mansoori, N., da Rocha, U. N., Shi, S., Cho, H., Karaoz, U., Loqué, D., Bowen, B. P., Firestone, M. K., Northen, T. R., and Brodie, E. L. 2018. Dynamic root exudate chemistry and microbial substrate preferences drive patterns in rhizosphere microbial community assembly. Nat. Microbiol. 3:470-480.

Zhang, F., Romheld, V., and Marschner, H. 1991. Release of zinc mobilizing root exudates in different plant species as affected by zinc nutritional status. J. Plant Nutr. 14:675-686. 